08

\title{
Влияние металлизации серебром и электронного облучения на процессы механической деформации полиимидных пленок
}

\author{
(ㄱ А.Д. Мурадов, ${ }^{1}$ К.М. Мукашев, ${ }^{1}$ Г.Ш. Яр-Мухамедова, ${ }^{1}$ Н.Е. Коробова ${ }^{2}$ \\ ${ }^{1}$ Казахский национальный университет им. аль-Фараби, \\ 050040 Алматы, Казахстан \\ ${ }^{2}$ Национальный исследовательский университет МИЭТ, \\ 124498 Москва, Россия \\ e-mail: abyl.muradov@mail.ru
}

(Поступило в Редакцию 24 января 2017 г.)

Исследовано влияние металлизации серебром и электронного облучения на физико-механические свойства полиимидных пленок. Металлический слой, импрегнированный в структуру полиимидной основы, составлял от 1 до $5 \mu \mathrm{m}$. Покрытия на поверхности содержали 80-97\% относительного серебряного зеркала в видимой и инфракрасной областях. Облучение производилось на линейном ускорителе ЭЛУ-6 со средней энергией пучка электронов $2 \mathrm{MeV}$, интегральном токе до $1000 \mu \mathrm{A} \mathrm{c} \mathrm{частотой} \mathrm{посылки} \mathrm{импульсов} 200 \mathrm{~Hz}$ и продолжительностью импульсов $5 \mu \mathrm{s}$. Поглощенная доза образцами составляла: 10, 20, 30 и $40 \mathrm{MGy.}$ Деформацию образцов производили при комнатной температуре в режиме одноосного растяжения на универсальной испытательной машине Instron 5982. Структурные изменения в композитных материалах в результате воздействия физических факторов изучались на рентгеновском дифрактометре ДРОН-2М на воздухе при температуре $293 \mathrm{~K}, \mathrm{Cu} K_{\alpha}$-излучением $\left(\lambda_{\alpha \mathrm{Cu}}=1,5418 \AA\right)$. Установлено значительное повышение механических характеристик в результате металлизации пленок по сравнению с чистой пленкой. Увеличение предела прочности на $\Delta \sigma=105 \mathrm{MPa} \mathrm{и} \mathrm{пластичности} \mathrm{на} \Delta \varepsilon=75 \%$ связано с особенностями изменения структуры металлизированных пленок и условиями их химического травления. Электронное облучение металлизированной полиимидной пленки ухудшает ее упругие и прочностные показатели, что вызвано образованием новых фаз в покрытии в виде оксида серебра. Концентрация этих фаз возрастала с увеличением дозы облучения, что также вызвано нарушением упорядоченной структуры материала в виде разрыва звеньев макромолекул полиимида и образованием новых фаз серебра в покрытии. Получена математическая модель, которая хорошо согласуется с экспериментальными данными и позволяет прогнозировать упругие свойства металлизированных серебром полиимидных пленок.

DOI: 10.21883/JTF.2017.11.45131.2174

\section{Введение}

Необходимость получения металлизированных полимерных материалов и исследование свойств связаны с широким их использованием в космической отрасли, электронике, а также для выпуска товаров широкого потребления [1]. Основные тенденции поиска новых материалов направлены на получение композитных пленок с различным распределением металлической фазы по толщине с сохранением механических характеристик [1]. Наиболее перспективными металлизированными полимерными материалами являются полиимиды, обладающие высокой термостойкостью, хорошими диэлектрическими характеристиками и небольшим коэффициентом расширения [2]. Важным вопросом в таких исследованиях является выявление влияния типа металлизированного покрытия, его структуры на механические свойства полимерного композитного материала. С другой стороны, важным является получение определяющих уравнений вязкоупругих сред для описания конкретного типа механического нагружения, что позволяет прогнозировать эксплуатационные характеристики материала при различных видах механических воздействий (статических, динамических и др.) [3-6].
Поэтому исследование вязкоупругих, прочностных и других механических характеристик металлизированных полимерных материалов, выявление влияния структуры покрытия на их механическое поведение, разработка методов прогнозирования их поведения представляется в настоящее время актуальной и важной задачей.

Целью настоящей работы было выявление влияния металлизации серебром и дозы электронного облучения на процессы механической деформации полиимидных пленок.

\section{Методика исследований}

Исследование металлизированных полиимидных (ПИ) пленок проводилось в два этапа: первый этап заключался в получении образцов металлизированных пленок, а второй - в изучении изменения механических свойств этих образцов и математическом моделировании механизма этого процесса.

Первый этап состоял из двух стадий. Первая стадия технологической цепи включала в себе получение ПИ пленок различной толщины на основе лака АБ-имид. Технологическая схема предполагала выкатывание лака через фильеры на когезионный слой ленточного транс- 


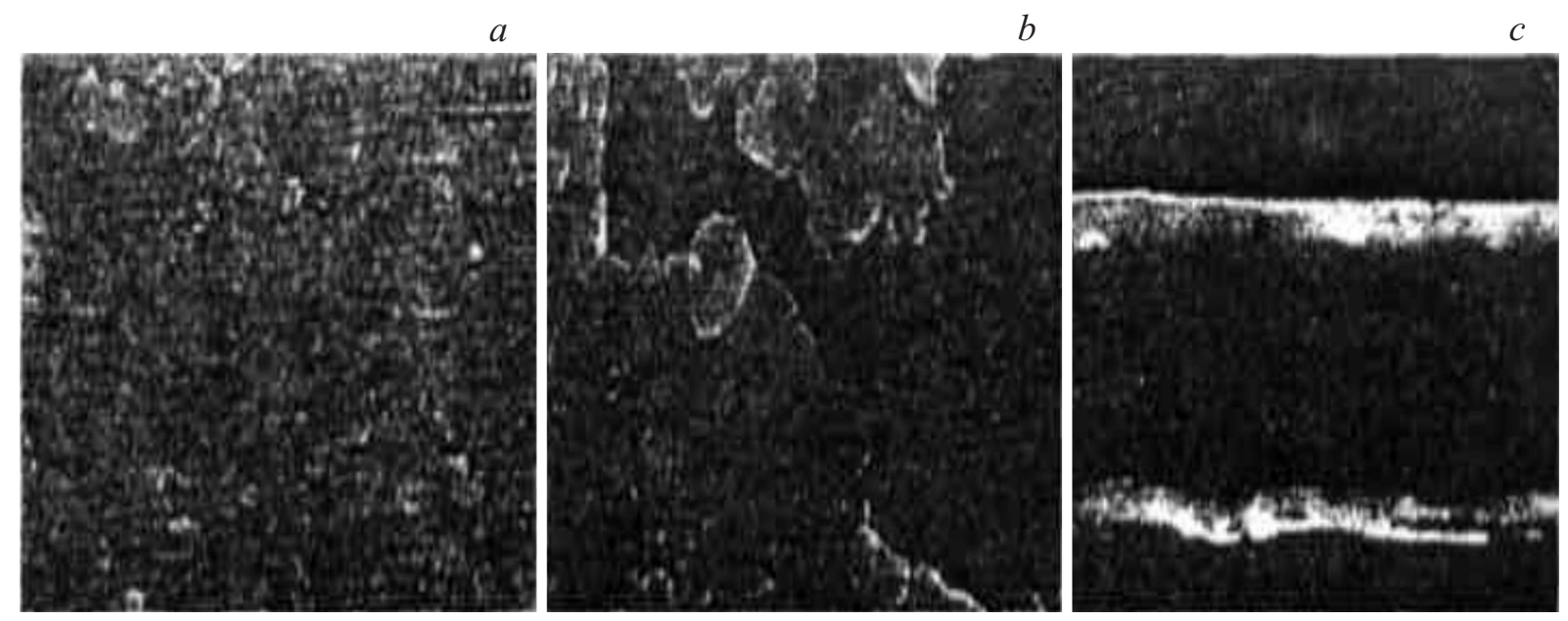

Рис. 1. СЭМ фотографии верхнего металлического слоя посеребренной ПИ пленки: $a-$ верхний слой, $b-$ подслой, $c-$ пленка в разрезе.

портера с последующей сушкой при $90^{\circ} \mathrm{C}$ и термической циклизации при $180^{\circ} \mathrm{C}$ в течение 1 и $2 \mathrm{~h}$ соответственно с закатыванием пленки в рулоны.

Вторая стадия заключалась в получении рулонной металлизированной пленки на основе последовательной обработки исходной ПИ пленки в органическом растворителе, в водно-спиртовом щелочном растворе, промывку, хелатирование восстанавливающимся металлом, промывку с диализом и термохимическое восстановление металла при $220^{\circ} \mathrm{C}$.

Металлизированные ПИ пленки были выполнены в виде сплошного (дву- или одностороннего) металлического слоя, импрегнированного в структуру полиимидной основы. Металлическая фаза из серебра была толщиной от 1 до $5 \mu \mathrm{m}$. Суммарная толщина конструкции образцов составляла $25-100 \mu \mathrm{m}$ в зависимости от толщины исходной пленки.

Металлизированные покрытия содержали на поверхности 80-97\% относительного серебряного зеркала в видимой и инфракрасной областях.

Из полученного рулона металлизированной ПИ пленки нарезались образцы шириной $5 \mathrm{~mm}$ и с рабочей длинной $50 \mathrm{~mm}$, которые затем делились на 5 групп с целью их дальнейшего облучения электронами при различных дозах. Одна группа образцов использовалась в качестве контрольных и не подвергалась облучению.

Облучение образцов производилось на линейном ускорителе ЭЛУ-6. Средняя энергия пучка электронов составляла $2 \mathrm{MeV}$ при интегральном токе до $1000 \mu \mathrm{A} \mathrm{c}$ частотой посылки импульсов $200 \mathrm{~Hz}$ и продолжительностью импульсов $5 \mu \mathrm{s}$. Поглощенная доза $(D)$ образцами каждой группы составляла соответственно: 10, 20, 30 и 40 MGy.

Далее образцы деформировались при комнатной температуре в режиме одноосного растяжения. Методология проведения механических испытаний основывалась на использовании универсальной испытательной машины Instron 5982 с программным обеспечением Bluehill 3, которая предназначена для определения механических характеристик различных материалов. В программе Bluehill 3 выбор метода испытаний является основой эксперимента, где назначается нужный вид статического испытания. Проведения испытаний основывались на ГОСТ 25.604-82 и американском стандарте АСТМ D3039/D 3039M-00.

Технические характеристики электромеханической машины Instron 5982: максимальная нагрузка $100 \mathrm{kN}$, погрешности измерения нагрузки и деформации $\pm 0.5 \%$ от измеряемой величины.

Изучение структурных характеристик полученных композитных материалов в результате воздействия вышеуказанных физических факторов было проведено на рентгеновском дифрактометре типа ДРОН-2М на воздухе при температуре $293 \mathrm{~K}, \mathrm{Cu} K_{\alpha}$-излучением $\left(\lambda_{\alpha \mathrm{Cu}}=1.5418 \AA\right)$ при скорости движения счетчика $2 \mathrm{deg} / \mathrm{min}$ и ленты $2400 \mathrm{~mm} /$ hour.

\section{Экспериментальные результаты и их обсуждение}

Известно, что оксиды оказывают некоторое каталитическое влияние на ход реакции имидизации по механизму основного катализа. В присутствии оксидов некоторых металлов амидо-кислотные фрагменты имидизуются с более высокими скоростями, чем в отсутствие катализатора, одновременно несколько повышается вязкость получаемых систем. После отжига количество нециклизованных имидных групп уменьшается, а термическая устойчивость ПИ пленки повышается.

Металлический слой создавался в результате формирования металлических частиц: вначале ионы $\mathrm{Ag}$ образуют на поверхности пленки небольшие кристаллы, которые растут за счет восстановления ионов серебра, диффундирующих на поверхность по системе пористых каналов. Морфология поверхностности наноструктури- 


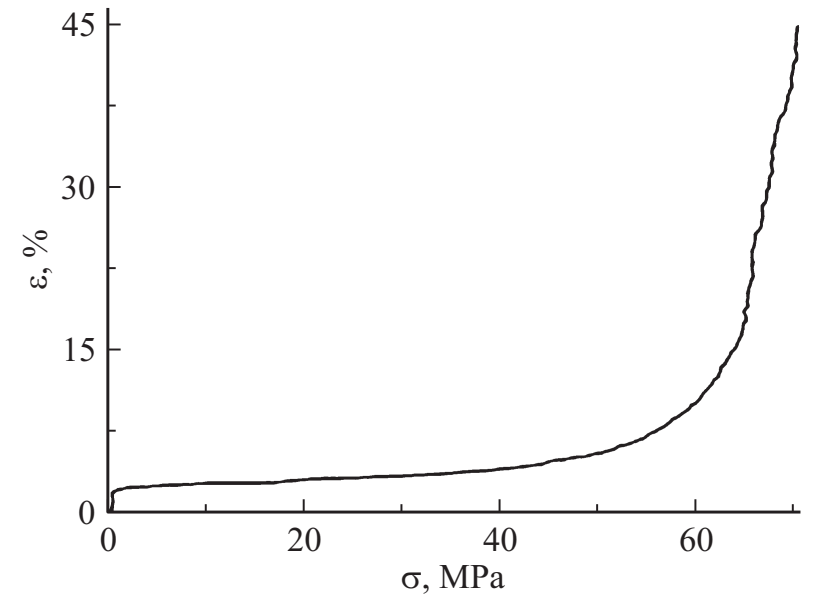

Pис. 2. Относительное удлинение чистой ПИ пленки при одноосном растяжении. 1 - чистая пленка, 2 - посеребренная пленка.

рованная и не однородная по объему поверхностного слоя. В результате внешний слой представляет собой плотноупакованные зерна металла размером около $50 \mathrm{~nm}$ (рис. 1,a). Зерна имеют размер 8-10нм в поверхностном слое и распределены островками между матричной основой полиимида. Существует строгий градиент распределения металла по объему пленки с максимальным содержанием металла на внешнем слое, убывающим по глубине материала (рис. $1, b, c)$.

Поверхность серебряного покрытия, формируемого на воздухе, отличается заметной неоднородностью со стороны подложки. Образующие микропоры являются каналами, по которым происходит транспорт катионов серебра к поверхности, что и объясняет островковую природу серебряного покрытия.

Отслоение (деламинация) металлического поверхностного слоя не наблюдается до разрушения цельности всего полимерного слоя при нагрузках не менее $160 \mathrm{MPa}$ (комнатные условия) и $100 \mathrm{MPa}\left(\right.$ свыше $200^{\circ} \mathrm{C}$ ).

Вначале были исследованы механические свойства чистой ПИ пленки при одноосном растяжении путем изучения зависимости относительного удлинения $(\varepsilon)$ от приложенной внешней механической нагрузки $(\sigma)$ до ее разрыва (рис. 2). Видно, что полный разрыв образца происходит при напряжении $\sigma=70 \mathrm{MPa}$ и относительном удлинении $\varepsilon=45 \%$.

На первых стадиях приложения нагрузки в пределах 0-1 МРа наблюдается резкий скачок удлинения на $3 \%$. Данное явление связано с тем, что в этот момент макромолекулы вещества быстро распрямляются вдоль направления действия нагрузки, и происходит их переход от глобульного состояния в протяженное. На участке приложенных напряжений от 1 до $40 \mathrm{MPa}$ наблюдается линейный рост относительного удлинения материала, в котором выполняется закон Гука, указывая на упругое его растяжение. Очевидно, в данной области происходит вытягивание макромолекул, которые растягиваются в виде волокон в направлении течения полимерной матрицы [6]. В образце развивается вынужденная эластичность, связанная с разрывом боковых связей у макромолекул $(-\mathrm{C}=\mathrm{O})$.

На интервале $\sigma=40-50 \mathrm{MPa} \mathrm{удлинение} \mathrm{образца} \mathrm{про-}$ исходит по нелинейному закону. Однако его упругие свойства сохраняются, но закон Гука не выполняется. Дальнейшее увеличение нагрузки $(\sigma \geq 50 \mathrm{MPa})$ приводит к пластическому течению образца. Последнее сопровождается экспоненциальным ростом удлинения и завершается разрывом образца. В этот момент в полимере происходят разрывы связей между бензольными кольцами, и он сам деструктурируется.

Влияние металлизации серебром ПИ пленки на ее механические свойства при одноосном растяжении представлено на рис. 3 в виде зависимости относительного удлинения $(\varepsilon)$ от приложенного напряжения $(\sigma)$ для необлученной чистой и металлизированной пленки.

Из рис. 3 видно, что металлизация пленки увеличивает ее пластические свойства (относительное удлинение достигает $120 \%$ ), а также увеличивает предел прочности - прилагаемое разрывное напряжение достигает $\sim 175 \mathrm{MPa}$. По сравнению с неметаллизированной пленкой относительное удлинение у металлизированной пленки возрастает на $\sim 90 \%$, а предел прочности на $\sim 135 \mathrm{MPa}$. Стоит отметить, что в месте разрыва исследуемой пленки явно виден сам полиимид, при этом покрытый слоем серебра полиамид остается на его краях. Это связано с методом получения этих пленок. В нашем случае металлизация серебром пленок была осуществлена методом химического травления металла.

По нашему мнению, изменения механических характеристик у металлизированного материала также связаны с методом получения этих пленок.

Из рис. 3 видно, что у металлизированных образцов (кривая 2) упругое удлинение по нелинейному закону

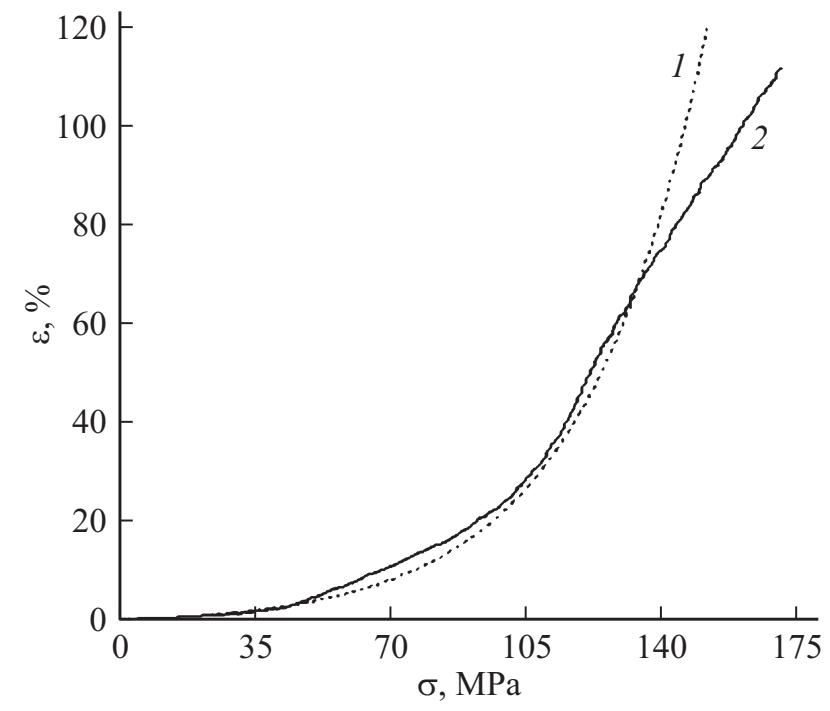

Рис. 3. Влияние металлизации серебром на механические свойства при одноосном растяжении необлученных ПИ пленок; 1 - чистая пленка, 2 - посеребренная пленка. 
Изменения модуля упругости $(E)$ металлизированной серебром ПИ пленки от дозы электронного облучения $(D)$

\begin{tabular}{c|c}
\hline Доза облучения $(D)$, MGy & Модуль упругости $(E), \mathrm{MPa}$ \\
\hline 10 & 31.1 \\
20 & 30.6 \\
30 & 30.1 \\
40 & 27.0
\end{tabular}

наблюдается в интервале нагрузок $\sigma=50-140 \mathrm{MPa}$. Пластическое течение образца возникает при нагрузках $\sigma \geq 140 \mathrm{MPa}$. Оно сопровождается экспоненциальным ростом удлинения и завершается его разрывом вследствие возникающих нарушений связей между бензольными кольцами матрицы. Весь этот процесс сопровождается одновременной деструкцией полимерного материала и разрывом связей между зернами металического покрытия.

Изменение относительного удлинения $(\varepsilon)$ от приложенной механической нагрузки $(\sigma)$ для металлизированных полимерных пленок можно представить в виде аналитического соотношения, которое описывает его поведение

$$
\varepsilon=\exp \left(\frac{\sigma}{E}\right)-1
$$

Разложение в ряд выражения (1) выглядит следующим образом:

$$
\varepsilon=\frac{\sigma}{E}+\frac{\sigma^{2}}{2 E^{2}}+\frac{\sigma^{3}}{3 E_{n}^{3}}+\ldots
$$

Здесь $E$ - модуль упругости композитного материала. Первый член этого уравнения $\left(\frac{\sigma}{E}\right)$ описывает поведение материала в упругой, линейной области относительного удлинения до $\sigma<50 \mathrm{MPa}$ и оно подчиняется закону Гука.

Второй член $\left(\frac{\sigma^{2}}{2 E^{2}}\right)$ уравнения (2) описывает поведение материала в упругой нелинейной области при $\sigma=50-140 \mathrm{MPa}$, когда процесс не подчиняется закону Гука. Третий член разложения $\left(\frac{\sigma^{3}}{3 E_{n}^{3}}\right)$ учитывает поведение материала в пластической области, для которого величина $E_{n}$ не является модулем упругости.

На основе полученных экспериментальных данных для необлученных металлизированных серебром ПИ пленок в упругой области было определено среднее значение модуля упругости, равное $31.7 \mathrm{MPa}$. Принимая за основу данное значение модуля упругости и исходя из выражения (2), была рассчитана теоретическая зависимость $\varepsilon=f(\sigma)$, представленная на рис. 4 в виде кривой 2. Нетрудно заметить, что полученные экспериментальные и теоретические зависимости хорошо согласуются между собой вплоть до нагрузок $\sim 140 \mathrm{MPa}$. Последующее же увеличение нагрузки приводит к росту пластической деформации композитного материала, и процесс заканчивается разрывом материала, поэтому в
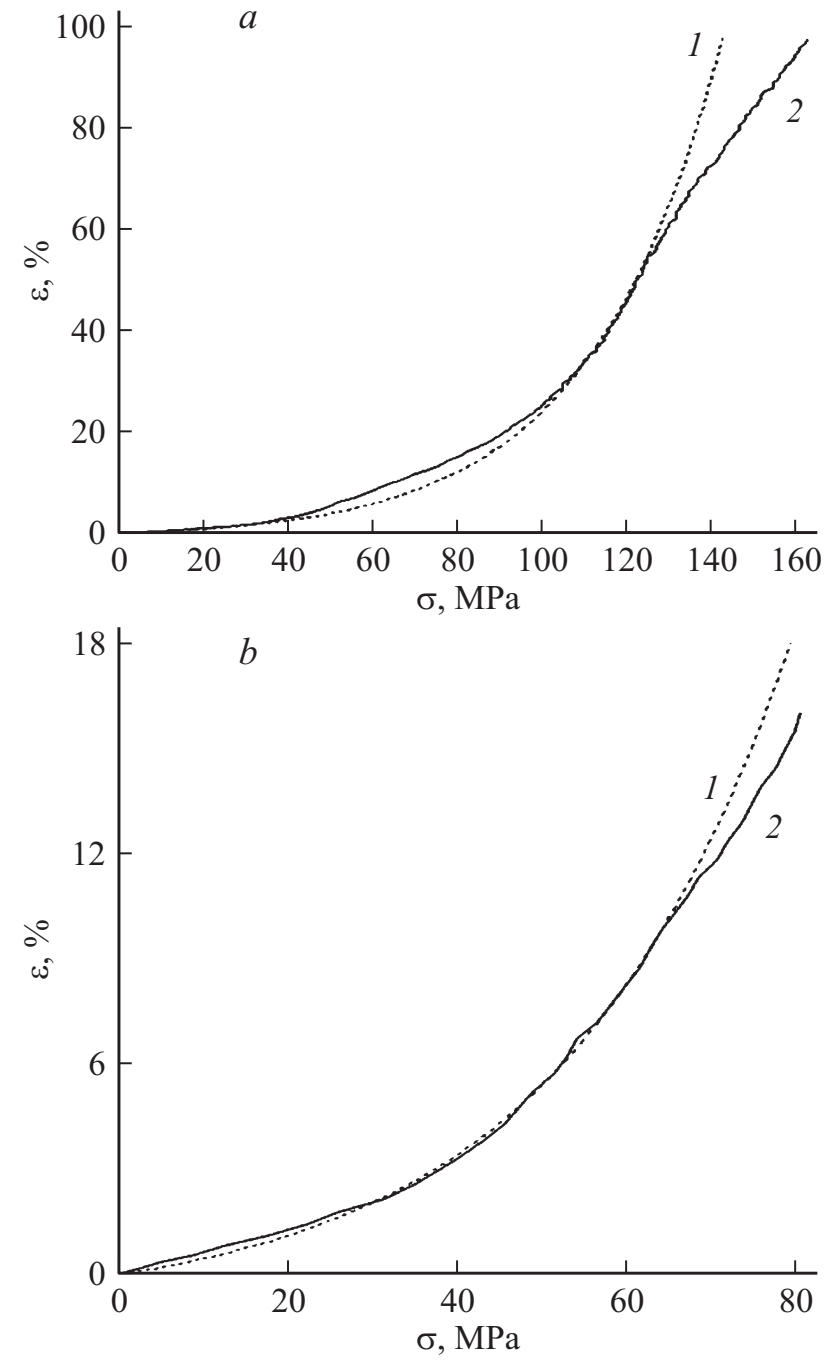

Рис. 4. Изменения относительных удлинений металлизированных серебром ПИ пленок при одноосном растяжении в зависимости от дозы электронного облучения; 1 - эксперимент; 2 - расчет $D=10 \mathrm{MGy}(a) ; D=40 \mathrm{MGy}(b)$.

теоретической модели для этого процесса деформации требуется рассматривать разложение функции $\varepsilon=f(\sigma)$ с учетом последующих членов разложения и параметров $E_{n}$.

Результаты исследования влияния различных доз электронного облучения на значения модуля упругости металлизированной серебром полиимидной пленки представлены в таблице. Из таблицы видно, что с увеличением дозы электронного облучения металлизированной серебром ПИ пленки уменьшаются значения ее модуля упругости, т.е. ухудшаются упругие и прочностные показатели.

Экспериментальные зависимости механических характеристик металлизированных серебром полиимидных пленок как следствия воздействия определенной дозы электронного излучения представлены на рис. 4.

Сравнивая представленные на рис. 4 данные с аналогичными характеристиками на рис. 3 , нетрудно уста- 


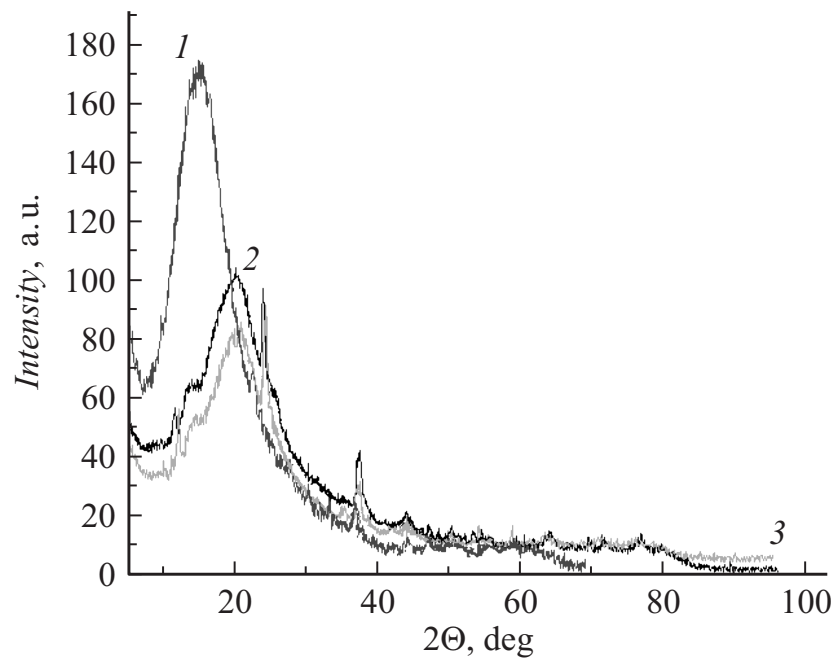

Рис. 5. Рентгенограммы металлизированных серебром ПИ пленочных материалов, подвергнутых механической деформации; 1 - исходная неразорванная необлученная металлизированная пленка $(D=0) ; 2-$ необлученная разорванная металлизированная пленка $(D=0) ; 3-$ разорванная облученная металлизированная пленка $(D=40 \mathrm{MГр})$.

новить отрицательную роль воздействия электронного облучения на механические свойства металлизированной серебром ПИ пленки. Видно, что с ростом дозы облучения механические характеристики металлизированных серебром ПИ пленок претерпевают заметное ухудшение. Прочность материала с повышением дозы от 10 до $40 \mathrm{MGy} \mathrm{снизилась} \mathrm{со} 160$ до $80 \mathrm{MPa}$, т. е. в 2 раза, а максимальное разрывное относительное удлинение упало со $\sim 100 \%$ до $\sim 18 \%$, т. е. уменьшилось более чем в 5 pas.

Применимость предлагаемой математической модели по описанию изменения механических характеристик облученных металлизированных серебром ПИ пленок демонстрируется на рис. 4 дополнительными кривыми. Математическая модель вполне удовлетворительно описывает процессы в упругой области зависимости и для облученных электронами материалов как в линейной, так и в нелинейной области кривых. Но модель не может описать скачок относительного удлинения для чистых ПИ пленок в начале приложения механической нагрузки в области $\sigma=0-1 \mathrm{MPa}$, поскольку в составе разложения уравнения (2) отсутствует соответствующий член.

На рис. 5 представлены рентгенограммы металлизированных серебром ПИ пленочных материалов, подвергнутых механической деформации до и после разрыва, а также электронному облучению дозой $40 \mathrm{MGy}$ в результате одноосного растяжения после разрыва. Видно, что для необлученной пленки в результате одноосного растяжения и разрыва интенсивность первого максимума (при $\sim 16^{\circ}$ ) уменьшается на $\sim 78$ а.u. по сравнению с неразорванной пленкой (кривая 1), со смещением в сторону возрастания на $\sim 6^{\circ}$ (кривая 2).Одноосная деформация с разрывом облученной пленки дозой 40 MGy вызывает дополнительное уменьшение интенсивности данного максимума на 20 а.u. по сравнению с неразорванной пленкой, с таким же сдвигом (кривая 3).

Первый максимум кривой 1 указывает на то, что исходный материал имел хорошо упорядоченную структуру. Уменьшение интенсивности и смещение пика в сторону возрастания углов (кривые 2 и 3) после вышеуказанных воздействий указывают на то, что в материалах нарушается упорядоченность структуры и происходят разрывы макромолекул полиимида. Эти изменения приводят к тому, что в результате комптоновского рассеяния рентгеновского излучения на новых центрах рассеяния пленок спектр смещается в сторону больших углов $\left(\theta>70_{1-}^{\circ}\right)$.

Возникновение и усиление дополнительных пиков при $\theta=25^{\circ}$ и $\theta=37^{\circ}$ указывает на то, что в результате этих воздействий в металлических покрытиях образуются новые фазы с диэлектрическими свойствами в виде оксида серебра. Усиление этих пиков связано с тем, что электронное облучение металлизированной пленки вызывает в ней рост новой фазы, которая увеличивается с дозой облучения.

Температурные исследования воздействия статической нагрузки (80\% от разрывного напряжения) показали, что температура, при которой разорвалась необлученная пленка, составила $290^{\circ} \mathrm{C}$ при относительном разрывном удлинении $\sim 90 \%$, а время от начало приложения нагрузки и до разрыва составило порядка $24 \mathrm{~min}$. С увеличением дозы облучения до $20 \mathrm{MGy}$ температура, при которой произошел разрыв, составила $230^{\circ} \mathrm{C}$. Увеличение дозы облучения до $40 \mathrm{MGy}$ привело к тому, что температура разрыва снизилась до $95^{\circ} \mathrm{C}$, а время от начала приложения нагрузки до разрыва $-8 \mathrm{~min}$, т. е. время воздействия нагрузки до наступления разрыва материала сократилось в 3 раза. Все это указывает на то, что с электронным облучением связано возникновение в композитном материале таких структурных изменений, которые приводят к ухудшению его термомеханических характеристик.

\section{Выводы}

1. Установлено, что металлизация серебром ПИ пленки значительно улучшает ее механические характеристики по сравнению с чистой пленкой, вызывая увеличение ее предела прочности на $\Delta \sigma=105 \mathrm{MPa} \mathrm{и} \mathrm{пластичности}$ на $\Delta \varepsilon=75 \%$. Такое изменение связано с особенностями структуры металлизированных пленок и условиями их химического травления.

2. Электронное облучение металлизированной серебром ПИ пленки ухудшает ее упругие и прочностные показатели. Модуль упругости уменьшается с увеличением дозы, что вызвано образованием новых фаз в покрытии в виде оксида серебра, концентрация которых возрастает с увеличением дозы. 
3. Ухудшение механических характеристик металлизированных серебром ПИ пленок в результате электронного облучения вызвано нарушением упорядоченной структуры материала в виде разрыва звеньев макромолекул полиимида и образованием новых фаз серебра в покрытии.

4. Предлагаемая математическая модель хорошо согласуется с экспериментальными данными в упругой области как для необлученных, так и облученных электронами при различных дозах. С помощью данной модели можно прогнозировать упругие свойства как необлученных, так и облученных электронами металлизированных серебром ПИ пленок.

\section{Список литературы}

[1] Кербер М.Л., Виноградов В.М., Головкин Г.С. и др. Полимерные композиционные материалы: структура, свойства, технология. СПб.: Профессия, 2008. 560 с.

[2] Михайлин Ю.А. Термоустойчивые полимеры и полимерные материалы. СПб.: Профессия, 2006. 623 с.

[3] Kravtsova V., Umerzakova M., Korobova N., Timoshenkov S., Matnishan A., Akhnazaryan T., Iskakov R. // Proc. of the IEEE-NANO 2015 - 15th International Conference on Nanotechnology. Rome, Italy, 2015. Article number 7388973. P. 262-265.

[4] Кабанов В.Я., Кудрявцев В.Н. // Химия высоких энергий. 2003. Т. 37. № 1. С. $3-7$.

[5] Шевченко A.A. Физикохимия и механика композиционных материалов. СПб.: Профессия, 2010. 224 с.

[6] Умбетова К., Кравцова В., Коробова Н., Искаков Р. // Изв. вузов. Сер. электроника. 2016. Т. 21. № 3. С. 201-207. 